\title{
Interactive comment on "Simultaneous
} measurement of the relative humidity dependent aerosol light extinction, scattering, absorption and single-scattering albedo with a humidified cavity-enhanced albedometer" by Jiacheng Zhou et al.

\section{Anonymous Referee \#2}

Received and published: 2 April 2020

General comments: Zhou et al. present an instrument characterization of a humidified cavity-enhanced albedometer (H-CEA) for simultaneous measurements of light extinction and scattering up to $88 \% \mathrm{RH}$. The instrument's performance was evaluated with ammonium sulfate, sodium chloride, and nigrosin aerosol particles. The manuscript is issues to be addressed and modified. 
I recommend adding a section comparing the versatility and accuracy of this setup with cell-reciprocal nephelometer (Mulholland and Choi, 1998; Mulholland and Bryner, 1994; Abu-Rahmah et al., 2006) and cavity ring-down techniques (Strawa et al., 2003 ) equipped with cosine sensor, which also allows simultaneous measurement light extinction and scattering in dry and humid conditions (Mikhailov et al., 2006).

Interactive comment

Section 3.1.1 How particle losses were evaluated? Please specify in detail.

Section 3.1.3 A single DMA, in addition to selected particles, transmits large multiply charged particles. How was this taken into account in the uncertainty analysis?

Section 3.2.1 Since E-AIM is an accurate thermodynamic model and can be used as a reference standard, I recommend first compare the measured optical coefficients with these calculated from E-AIM-based values. The obtained difference should be discussed and indicated in Table 1.

Section 3.2.1, Fig.6 and Fig.7 As the $\mathrm{RH}$ measured with $\mathrm{T} / \mathrm{RH}$-sensor-2 is lower than actual $\mathrm{RH}$ by $\sim 2 \%$ (Amm. sulfate measured $\mathrm{DRH}=77-78 \%$ vs. $80 \%$ ) the experimental $f(R H)$ values must exceed the model coefficients especially at high $\mathrm{RH}$, which contradicts the data presented in Fig. 6 and partially given by Fig.7. What is the $\mathrm{RH}$ difference between T/RH sensor-2 (input) and T/RH sensor-3 (output)? Due to water vapor sorption on the huge setup surface, the $\mathrm{RH}$ difference will be time-dependent. I recommend checking out the $\mathrm{RH}$ difference vs. time at least at $\mathrm{RH}>85 \%$. According to Fig. 2, a full measurement cycle was $20 \mathrm{~min}$. If so, then it is likely that in this short time, the thermodynamic equilibrium was not reached, and real $\mathrm{RH}$ was lower than that measured by $\mathrm{T} / \mathrm{RH}$ sensor- 2 . As a compromise, the average $\mathrm{RH}$ can be used for data plotting. Please consider the issue outlined above.

The data should be made available in a FAIR aligned repository. Making data "available upon request to the author" is inconsistent with the AMT data policy

Printer-friendly version

Discussion paper 
(https://www.atmospheric-measurement-techniques.net/about/data_policy.html).

References:

AMTD

Abu-Rahmah, A., Arnott, W. P., and Moosmüller, H. Integrating nephelometer with a low truncation angle and an extended calibration scheme, Meas. Sci. Technol. 17, 1723-1732, 2006.

Interactive

comment

Mikhailov, E. F., S. S. Vlasenko, I. A. Podgorny, V. Ramanathan, and C. E. Corrigan. Optical properties of soot-water drop agglomerates: An experimental study, J. Geophys. Res., 111, D07209, doi:10.1029/2005JD006389, 2006.

Mulholland, G. W., and N. P. Bryner (1994), Radiometric model of the transmission cell-reciprocal nephelometer, Atmos. Environ., 28, 873- 887.

Mulholland, G. W., and M. Y. Choi. Measurement of the mass specific extinction coefficient for acetylene and ethene smoke using the Large Agglomerate Optics Facility, paper presented at 27th International Symposium on Combustion, Combust. Inst., Boulder, Colo., 2 - 7 Aug. 1998.

Strawa, A. W., Castaneda, R., Owano, et al. The Measurement of Aerosol Optical Properties Using Continuous Wave Cavity Ring-Down Techniques, J. Atmos. Oceanic Technol., 20, 454-465, 2003.

Interactive comment on Atmos. Meas. Tech. Discuss., doi:10.5194/amt-2020-6, 2020. 